\title{
Empresariamento urbano e city marketing: reflexões a partir da cidade de Belo Horizonte
}

\author{
Luciano dos Santos Diniz ${ }^{1}$ \\ Ana Carolina Pioto Magalhães ${ }^{2}$ \\ Paulo Fernandes Sanches Junior ${ }^{3}$
}

\begin{abstract}
Resumo
A globalização da economia e a inserção das cidades na competitiva rede da economia internacional tornam a disputa por investimentos financeiros, criação de empregos, atração de turistas e moradores solventes cada vez mais acirrada. A partir da implementação de técnicas de gestão do denominado "empresariamento urbano", as cidades, na condição de mercadorias, são adequadas à ordem econômica mundial, mediante a afirmação de sua competitividade e respectivas vantagens locacionais. O plano de gestão estratégica e o city marketing surgem como importantes instrumentos do planejamento urbano atual, destinados a fomentar, respectivamente, o crescimento econômico e a "venda" da cidade no cenário internacional, mediante a promoção de uma imagem de cidade que projete os seus principais "produtos" no exterior. Diante deste cenário, este artigo busca analisar as práticas de city marketing adotadas pela gestão municipal de Belo Horizonte para a promoção da cidade no mercado interurbano. Para tanto, foi utilizada uma abordagem qualitativa na pesquisa, de natureza descritiva, recorrendo às pesquisas bibliográfica, documental e de levantamento para a coleta de dados. A pesquisa concluiu que Belo Horizonte está completamente inserida na lógica do "empresariamento urbano", o que leva a gestão urbana a assumir objetivos que visam não somente o bem-estar da população, mas também as demandas dos detentores de capitais e possíveis investidores da cidade. Diante desta lógica, o poder público utiliza, fundamentalmente, as seguintes ferramentas do city marketing em Belo Horizonte: infraestrutura, branding, promoção de eventos e participação popular.
\end{abstract}

Palavras-chave: Empresariamento urbano. Planejamento estratégico. City marketing. Belo Horizonte

\section{Urban entrepreneurship and city marketing: reflections from the city of Belo Horizonte}

\begin{abstract}
The globalization of the economy and the insertion of cities in the competitive network of the international economy, makes the competition for financial investments, job creation, tourists and satisfied residentes increasingly fierce. From the implementation of management techniques called "urban entrepreneurship" (HARVEY, 1996), cities, in the condition of goods, are adapting themselves to the world economic order, by affirming their competitiveness and respective locational advantages. Strategic management plan and city marketing emerge as important instruments of current urban planning, aimed at promoting, respectively, economic growth and the "sale" of the city on the international stage, by promoting an image of the city that projects its main "products" abroad. Given this scenario, this article seeks to analyze the city marketing practices adopted by the municipal management of Belo Horizonte to promote the city in the interurban market. Therefore, a qualitative approach was used in the research, that contains a descriptive nature, using bibliographic, documentary and survey research for data collection. The research concluded that Belo Horizonte is completely inserted in the logic of "urban entrepreneurship", which leads the urban management to assume objectives that aim not only the well-being of the population, but also the demands of the capital holders and possible investors of the city. In view of this logic, the Government uses, fundamentally, the following tools of city marketing in Belo Horizonte: infrastructure, branding, promotion of events and popular engagement.
\end{abstract}

Keywords: Urban entrepreneurship. Strategic planning. City marketing. Belo Horizonte.

${ }^{1}$ Doutorado em Ciências Sociais (PUC-SP). Professor do Centro Federal de Educação Tecnológica de Minas Gerais (CEFET/MG). https://orcid.org/0000-0001-5396-9999 Email: lucianodiniz@cefetmg.br

${ }^{2}$ Graduação em Administração (CEFET/MG). Email:carol_pioto@hotmail.com

${ }^{3}$ Doutorado em Engenharia Civil (UNICAMP). Professor do Centro Federal de Educação Tecnológica de Minas Gerais (CEFET/MG). https://orcid.org/0000-0002-1786-867X Email:sanches@cefetmg.br 


\section{Introdução}

No final do século XX, a profunda recessão de 1973, agravada pelo choque do petróleo, desencadeou profundas alterações no capitalismo de regime fordista, iniciando um conturbado período de reestruturação econômica, social e política dos Estados. O redimensionamento das atividades estatais foi acentuado pelo neoliberalismo e pela globalização, dado ao aumento da competitividade internacional e à redução da capacidade dos Estados nacionais de proteger suas empresas e seus respectivos trabalhadores (BRESSERPEREIRA; CUNILL-GRAU, 1999; THEODORE; PECK; BRENNER, 2009). As mudanças representavam os primeiros indícios de passagem ao regime de "acumulação flexível", o qual, segundo Harvey (2011, p. 140), apoia-se "na flexibilidade dos processos de trabalho, dos mercados de trabalho, dos produtos e dos padrões de consumo".

Nesse cenário, os mercados nacionais/globais e as operações globalmente integradas passam a demandar lugares com infraestrutura física, mão de obra qualificada, serviços especializados, telecomunicações, etc., para viabilizar a realização dos novos processos produtivos (SASSEN, 1998). De acordo com Santos (2006), a nova organização espacial do lugar acaba sendo estimulada também pelas forças internas do capital, que passam a ditar o modo como os territórios devem se organizar a fim de favorecer a expansão capitalista.

O tecido urbano é, então, moldado para permitir o funcionamento da economia global e a circulação, em diferentes escalas, de objetos (dinheiro, maquinário, matérias-primas, bens de consumo) e de sujeitos (migrantes, trabalhadores, turistas, consumidores), bem como de dados, imagens e informação (RODRIGUES, 2010). Em consequência, um novo espaço se constitui à escala mundial (neocapitalismo), alicerçado nas redes financeiras, da informação e da circulação, que integram e desintegram o local, o regional, o nacional, o mundial (LEFEBVRE, 2006).

Santos (2006) acredita que isso ocorre devido à migração dos investimentos, até então no meio industrial, para o setor financeiro, gerando uma grande bolha especulativa, que encontrou na acumulação flexível uma saída para a crise econômica. Assim, além de atraídos por taxas de juros, mudanças cambiais e programas de privatização, esse capital especulativo encontra na valorização do território e do espaço uma nova forma de investimento; trazendo consigo um novo regime de acumulação predominantemente financeiro, definido por Chesnais (2001, p. 9) como a "mundialização do capital".

Em meio a este conturbado cenário socioeconômico, as cidades centrais e periféricas 
começam a apoiar-se cada vez mais em estratégias até então voltadas para o meio privado como forma de sobrevivência dos espaços urbanos, dando início ao que Harvey (1996) denomina de "empresariamento urbano", um novo modelo de gestão utilizado pelos poderes públicos para promover o desenvolvimento socioeconômico de suas cidades em um cenário de erosão econômica, austeridade fiscal e forte competição interurbana.

O novo modelo de empresariamento urbano, de acordo com Fix (2004), impõe uma lógica na qual as ações e políticas públicas se orientam para áreas de interesse do mercado. As cidades, na condição de mercadorias, são adequadas à ordem econômica mundial, mediante a afirmação de sua competitividade e respectivas vantagens locacionais (HARVEY, 1996; VAINER, 2002). A cidade passa a ser, ela mesma, o objeto da especulação capitalista, (re)estruturandose e (re)produzindo-se para, desta forma, ser vendida com uma imagem atraente e com potencial de valorização.

Nesse contexto, os planos de gestão estratégica e o city marketing surgem como importantes instrumentos do planejamento urbano atual, destinados a fomentar, respectivamente, o crescimento econômico e a "venda" da cidade no cenário internacional. Isto vem sendo realizado mediante a promoção de uma imagem de cidade que projete os seus principais "produtos" no exterior, como forma de atrair novos investimentos, empresas, moradores e turistas (GOTTDIENER; FEAGIN, 1989; RAINISTO, 2003; WARD, 2004).

Diante deste objetivo, os desafios de desenvolvimento econômico ultrapassam os limites das políticas públicas, tornando-se também desafios de mercado, uma vez que a competição entre nações e territórios gera a necessidade de se garantir posicionamento no cenário internacional, objetivo este alcançado a partir das vantagens competitivas (KOTLER; GERTNER, 2002).

A cidade de Belo Horizonte, que teve seu primeiro plano estratégico ${ }^{1}$ elaborado em 2009, durante a gestão do então prefeito Márcio Lacerda, para definir as práticas a serem adotadas para a Copa do Mundo de 2014, busca, cada vez mais estabelecer-se neste cenário, utilizando o city marketing, por meio de políticas públicas de promoção da cidade e de seus atrativos para potencializar sua economia. Diante disso, o presente estudo analisa as ferramentas do city marketing adotadas pelo poder público municipal, a partir de 2009, para a promoção da cidade de Belo Horizonte no mercado interurbano.

Trata-se de um estudo de abordagem qualitativa e natureza descritiva, no qual foram

1 "Planejamento estratégico de Belo Horizonte 2030: a cidade que queremos", doravante denominado PEBH. COLÓQUIO - Revista do Desenvolvimento Regional - Faccat - Taquara/RS - v. 18, n. 1, jan./mar. 2021 
utilizadas pesquisas bibliográfica, documental e entrevistas semiestruturadas, com amostra não probabilística por conveniência, com gestores públicos de órgãos ligados às políticas de planejamento estratégico, ao turismo, à atração de investimentos e à internacionalização de Belo Horizonte.

\section{Os aspectos do empresariamento urbano na dinâmica urbana}

Diante do protagonismo adquirido pelas cidades no mundo globalizado, os governos municipais reformularam a forma de planejamento e gestão urbana, passando a implementar políticas urbanas neoliberais (desregulamentação do mercado, privatização de serviços, coalizões público-privadas, etc.) e, a partir de ambiciosos projetos estratégicos, atuam no sentido de flexibilizar suas estruturas produtivas e comerciais, atrair investimentos, promover o turismo, etc. (CASTELLS; BORJA, 1996; THEODORE; PECK; BRENNER, 2009). Em consequência, deixaram de ser apenas regulamentadores urbanos, preocupando-se, também, com o crescimento econômico e com a atração de investimentos, formando alianças destinadas ao fomento ou à administração do desenvolvimento urbano.

Harvey (1996) define esse momento como a passagem do gerenciamento urbano para o empresariamento. A partir deste momento, surge um consenso de que benefícios são obtidos por cidades que assumem essa postura empreendedora em relação ao desenvolvimento econômico. Denotando, de igual modo, um projeto de cidade em que se articulam, paradoxalmente, três analogias que o constituem: "a cidade é uma mercadoria, a cidade é uma empresa, a cidade é uma pátria" (VAINER, 2002, p. 77).

A adaptação e a participação das cidades no cenário de investimentos internacionais são indispensáveis para sua sobrevivência. Pinto (2001) acredita que a adoção das ferramentas do urbanismo empreendedor auxilia na realização dessa inserção, sendo uma delas o planejamento estratégico. De acordo com Sánchez (1999), os planos estratégicos propõem ações de médio a longo prazo, cujos projetos fundamentais voltam-se para o crescimento e o desenvolvimento urbano, principalmente no setor econômico. O empresariamento urbano seria, então, uma forma de gestão direcionada à atração de investimentos, recursos financeiros, empresas, postos de trabalho, turistas e moradores solventes para a cidade, a fim de garantir seu desenvolvimento, num cenário de acirrada competição interurbana (HARVEY, 1996).

O modelo de planejamento estratégico - incialmente utilizado no setor público do Reino Unido, a partir de 1979, pelo governo de Margareth Thatcher -, tornou-se popular após sua 
aplicação na cidade de Barcelona, ao projetar ações urbanísticas voltadas para a criação e revitalização dos espaços urbanos, para que a cidade sediasse os Jogos Olímpicos de 1992 (ARAÚJO, 2011; SILVA, 2012). O planejamento estratégico da cidade de Barcelona consistiu na primeira experiência aprofundada e de sucesso na Europa. O "modelo Barcelona"2 de regeneração urbana difundiu-se internacionalmente, como meio de implementação de uma "nova base econômica, infraestrutura urbana, qualidade de vida, integração social e governabilidade" (CASTELLS; BORJA, 1996, p. 155).

Em meio à necessidade de adaptação das cidades a este novo contexto econômicosocial, Harvey (1996) acredita que a adoção de quatro estratégias combinadas do empresariamento urbano favorece o desenvolvimento local, garantindo uma maior atratividade às cidades. Tais estratégias, contudo, não devem se restringir à promoção do desenvolvimento econômico, excluindo as questões sociais; sob pena de direcionar as políticas públicas para o atendimento dos interesses das classes dominantes.

A primeira estratégia consiste em explorar os recursos que as cidades possuem e as vantagens competitivas que as mesmas oferecem para a produção de bens e serviços, podendo se tratar de recursos naturais, de localização ou até mesmo criados através de investimentos públicos e privados, a partir de infraestruturas físicas ou do incentivo à criação e à tecnologia (HARVEY, 1996). Os recursos criados podem ser encontrados em forma de infraestruturas físicas ou por intermédio de incentivos do setor público. Atualmente, é difícil encontrar grandes empreendimentos imobiliários que não contem com incentivos governamentais, seja pelo abatimento de impostos, redução de encargos para implantação ou até mesmo pela baixa salarial da mão de obra (ARAÚJO, 2011).

A segunda estratégia tem como foco aumentar a competitividade das cidades por meio da divisão espacial do consumo. Ou seja, além de simplesmente tentar atrair investimentos para a região, o poder público investe em atrativos turísticos e de consumo, gerando uma base para o consumo em massa (HARVEY, 1996). As cidades devem ser transformadas em lugares dinâmicos, inovadores, criativos e seguros, onde se encontra qualidade de vida, cultura e qualidade do meio urbano. Assim, há uma restruturação da morfologia urbana, a partir da introdução de equipamento comerciais e de seviços, como: centros de lazer, estádios, shopping centers, praças de alimentação, centros de convenções, teatros e outras infraestruturas,

\footnotetext{
${ }^{2}$ Conforme Abrantes (2010, p. 1), “entende-se por Modelo Barcelona o conjunto de intervenções de reestruturação urbana realizadas a partir dos anos 80 na cidade de Barcelona, com recurso ao planeamento (sic) estratégico e operacional e à gestão público-privada, numa perspectiva de desenvolvimento social e económico (sic) da cidade."
} 
evidenciando esta nova imagem da cidade (HARVEY, 1996). As cidades adotam, desta forma, estratégias que revelem seus melhores recursos, e que vendam da maneira mais positiva possível a imagem do lugar. A promoção dessas qualidades se dá pela utilização do city marketing, que tem como principal objetivo justamente a promoção de uma imagem atrativa e positiva da cidade ("cidade global", "cidade criativa", "cidade verde", "cidade sustentável", "cidade para todos"), para, assim, atrair recursos para a mesma (ARAÚJO, 2011; DELGADILLO, 2014).

A terceira estratégia diz respeito a transformação da cidade em um local de controle e funções de comando de altas operações financeiras, de concentração ou processamento de informações. Essa estratégia requer infraestruturas específicas, ligadas aos serviços de transportes e comunicação, destinadas a minimizar o tempo e os custos das transações. (HARVEY, 1996). Assim, altos investimentos e eficiência são necessários para garantir a conservação e qualidade da rede de comunicação urbana, como portos, aeroportos, estradas, telefonia e internet. As cidades que adotam e conseguem adaptar-se a essa estratégia são denominadas como cidades globais, definidas por Carvalho (2000) como o "ponto nodal" entre a economia local e o mundo, possuindo em seu território atividades econômicas e de serviços de alta tecnologia. Logo, seguindo a visão de Harvey (1996), essas cidades representam o período pós-industrial, sendo a exportação de serviços a nova base da economia urbana.

A última estratégia, por sua vez, visa garantir a redistribuição de excedentes por parte dos governos centrais, o que garante maior possibilidade de ações e investimentos públicos em proveito dos cidadãos (HARVEY, 1996). As quatro estratégias encontram-se sintetizadas no quadro 1 e, segundo Harvey (1996) não são mutuamente excludentes, sendo que em alguns cenários a utilização de uma serve como viabilizadora de outra.

Kotler et al. (1993) e Ferreira (2005) sublinham que a elaboração do plano estratégico deve começar pela realização de um diagnóstico estratégico - baseado na matriz SWOT, da Harvard School (conhecido como FOFA - forças, fraquezas, oportunidades e ameaças) -, que evidencie os aspectos internos e externos da cidade. Pelo primeiro, analisa-se as características e especificidades da cidade ("o que é") e os principais fatores e atividades de desenvolvimento ("o que faz"), determinando-se, a partir daí, seus aspectos positivos (potencialidades/forças) e negativos (debilidades/fraquezas). A análise externa, por sua vez, tende a avaliar as influências dos sistemas regionais, nacionais e internacionais sobre o território da cidade, a fim de determinar as oportunidades e as ameaças que a envolvem. 
Quadro 1 - Estratégias de Harvey e os aspectos trabalhados

\begin{tabular}{|c|c|c|c|c|}
\hline \multirow[b]{2}{*}{$\frac{\text { 迹 }}{\text { 岕 }}$} & 1 ESTRATÉGIA & 2ㅇ ESTRATÉGIA & 3 ESTRATÉGIA & 4 ESTRATÉGIA \\
\hline & $\begin{array}{l}\text { Explorar recursos e } \\
\text { vantagens } \\
\text { competitivas }\end{array}$ & $\begin{array}{c}\text { Aumentar a } \\
\text { competitividade através } \\
\text { da divisão espacial do } \\
\text { consumo }\end{array}$ & $\begin{array}{c}\text { Transformação da Cidade em } \\
\text { local de controle e funções de } \\
\text { comando de altas operações } \\
\text { financeiras }\end{array}$ & $\begin{array}{c}\text { Garantir a redistribuição } \\
\text { dos excedentes por } \\
\text { parte do governo local }\end{array}$ \\
\hline $\begin{array}{l}\text { on } \\
\frac{\underline{L}}{4} \\
\frac{a}{4}\end{array}$ & $\begin{array}{l}\text { - Recursos naturais; } \\
\text { - Localização } \\
\text { estratégica; } \\
\text { - Investimento } \\
\text { público; } \\
\text { - Estrutura física. }\end{array}$ & $\begin{array}{l}\text { - Centros de lazer; } \\
\text { - Shopping centers; } \\
\text { - Teatros, cinemas, } \\
\text { museus; } \\
\text { - Praças de alimentação; }\end{array}$ & $\begin{array}{l}\text { - Realização de altas } \\
\text { transações financeiras; } \\
\text { - Ampla rede de comunicação; } \\
\text { - Portos, aeroportos, } \\
\text { ferroviárias; } \\
\text { - Cidade "nodal" entre } \\
\text { economia local e global. }\end{array}$ & $\begin{array}{l}\text { - Qualidade de vida da } \\
\text { população; } \\
\text { - Infraestrutura que } \\
\text { atenda aos cidadãos; } \\
\text { - Participação popular. }\end{array}$ \\
\hline
\end{tabular}

Fonte: Elaborado pelos autores a partir de Harvey (1996).

Nesta análise avalia-se as tendências de evolução da cidade, distinguindo-se entre tendências "pesadas" e tendências "emergentes", conforme a visão estratégica formulada: projeção internacional, nacional e/ou regional; inserção competitiva nas redes de cidades; melhoria da qualidade de vida da população citadina; coesão social; sustentabilidade ambiental; competividade econômica; entre outras. De maneira que, no projeto estratégico da cidade, sejam realçados, em particular, aqueles que poderão ser os atributos e recursos distintivos que garantam uma vantagem competitiva à mesma.

A produção orquestrada de uma imagem de cidade dinâmica, empreendedora, socialmente integrada, apta a receber capital externo e estimular a circulação do capital e das pessoas "adequadas", se bem-sucedida, atrai investimentos econômicos e outras formas de progresso (KOTLER et al., 1993).

Para garantir a obtenção destas vantagens competitivas o marketing, ferramenta até então pertencente ao meio privado, começa a ser adaptado para o cenário urbano, levando à criação do city marketing, estratégia utilizada para promover a cidade e seus atrativos (SILVA, 2015). A utilização dessa estratégia torna a cidade um lugar onde "tudo é objeto de consumo estético e contemplativo" (SÁNCHEZ, 1999, p. 126). Como alude Harvey (1996), a cidade e suas características são expostas na vitrine comercial global.

De acordo com Almeida e Engel (2017), o city marketing, assim como o marketing empresarial, tem o intuito de vender um produto, que neste caso, trata-se da cidade, tornandoa atraente não só para seus moradores, mas para possíveis investidores e para o capital internacional. Para Rainisto (2003), os lugares precisam atrair exportações, atrair indústrias e investidores, ampliar a captação de visitantes, residentes e eventos, precisando recorrer as estratégias de marketing e branding para que isso ocorra. 
Deste modo, torna-se fundamental que a todo momento boas práticas de marketing sejam realizadas para alavancar a cidade. Segundo Almeida (2004), quatro aspectos se tornam fundamentais neste processo:

(i) Assegurar a satisfação dos cidadãos, investidores e visitantes, fornecendo serviços atrativos e infraestrutura adequada;

(ii) Criar atrações com o objetivo de gerar qualidade de vida, tornando possível que as empresas estabelecidas se mantenham e atraindo novos negócios;

(iii) Promover e divulgar as melhorias ocorridas na qualidade de vida, gerando uma imagem positiva da cidade;

(iv) Gerar apoio da população, permitindo que ela participe da criação da imagem da cidade, atraindo investimentos e visitantes.

Araújo (2011, p.5), define o city marketing como uma prática que tem como objetivo "promover a publicidade das cidades e mostrar apenas os pontos, lugares, comércios, centros de consumo e diversão da melhor forma possível e chamar a atenção dos que possuem recursos financeiros para investir, gastar, consumir e financiar o crescimento das cidades".

Segundo Araújo (2011, p. 5-6), “a caracterização e efetiva demonstração de potencial receptivo das cidades acabam por colocá-las em grupos seletos de grandes investimentos internacionais", uma vez que a promoção de eventos e festividades "acabam por trazer não apenas recursos de melhoras por parte dos poderes públicos e privados nacionais e sim acarreta em projetar tais cidades para o recebimento em investimentos internacionais".

A utilização de técnicas que gerem retorno para a cidade deve, deste modo, estar em constante evolução, para que a cidade possa continuar a se destacar em meio à competição interurbana. Assim, de acordo com Ocke e Ikeda (2014), além das questões associadas ao marketing de lugar, percebe-se, nos últimos anos, uma maior atenção dos gestores para a perspectiva de branding, ou seja, há uma maior preocupação com a marca e com a imagem vendida da cidade.

Como é colocado por Dallabrida, Tomporoski e Sark (2016), embora muitas vezes o conceito de city marketing e branding sejam confundidos, é importante perceber a diferença entre eles, pois, enquanto o city marketing foca na promoção do lugar como um todo, a perspectiva de place branding está mais ligada à administração da marca, através da divulgação da sua identidade, gerando a criação de valor.

Para Kavaratzis (2005), o place branding consiste na utilização das qualidades, imagens e dos estereótipos do lugar e das pessoas que vivem nele 
para promover a cidade. Tornando-se a ligação entre o que é realizado pelo governo local e a percepção dos cidadãos. Deste modo, de acordo com o autor, branding está diretamente ligado a percepção dos consumidores.

De acordo com Almeida (2004), no place branding a cidade contrata uma agência de publicidade para desenvolver e divulgar a imagem e marca da cidade. Almeida (2004, p. 24) ainda afirma que "os custos e a eficácia da estratégia de imagem dependem dos verdadeiros atributos do local e da imagem actual (sic)".

Kavaratzis (2005) afirma que a comunicação do place branding é realizada de duas maneiras, sendo elas a comunicação primária e a secundária. Nesse aspecto, a comunicação primária está relacionada com a divulgação das ações da cidade, sendo que a comunicação em si não é o objetivo principal (divulgação de informações ligadas ao planejamento urbano, projetos de infraestrutura, projetos administrativos e serviços públicos). Por sua vez, a comunicação secundária diz respeito à comunicação intencional da divulgação da imagem da cidade, através de propagandas, eventos públicos e logo, entre outras. Esta comunicação deve estar de acordo com o restante das práticas de marketing desenvolvidas pela cidade.

Logo, o place branding diz respeito a utilização de estratégias para formar a marca e imagem da cidade tanto internamente quanto externamente. De acordo com Ocke e Ikeda (2014, p. 676), "o branding de lugar refere-se à aplicação de estratégias adequadas, a fim de diferenciar cidades, regiões e países da concorrência, no que diz respeito ao desenvolvimento econômico, social, político e cultural".

Ocke e Ikeda (2014) completam afirmando que, atualmente, os gestores públicos perceberam que, em meio a competição interurbana cada vez mais acirrada e a dificuldade cada vez maior de gerar atrativos únicos na cidade, o investimento em infraestrutura, centros de consumo e equipamentos culturais torna-se insuficiente para atrair investimentos, empresas, turistas e satisfazer os habitantes, sendo assim a utilização do branding para criar a imagem do lugar torna-se uma excelente ferramenta para valorizar sua atratividade e proporcionar desenvolvimento econômico.

A utilização do city marketing torna-se, então, ferramenta essencial nessa nova perspectiva urbana, sendo o responsável pela promoção e "venda" da cidade no cenário internacional, a partir das especificidades locais: realidade; recursos naturais, humanos e locacionais disponíveis; objetivos estratégicos e público a atingir. Deste modo, as estratégias adotadas nesse modelo passam a ser instauradas e copiadas por praticamente todas as cidades ao redor do mundo (KOTLER; GERTNER, 2002). 
Contudo, face ao caráter especulativo dos investimentos, o êxito das ações destinadas à "venda" da cidade está condicionado à criação de uma imagem urbana atraente (HARVEY, 2005). A criação de uma "marca" para a cidade consiste, então, no diagnóstico de suas potencialidades econômicas e sociais, bem como na avaliação dos aspectos positivos e negativos que deverão ser destacados ou modificados na divulgação da imagem citadina (COMPANS, 1999).

Vainer (2002) aponta que, como o empresariamento urbano considera muito mais o âmbito econômico da cidade do que seus aspectos sociais, verifica-se uma contradição entre a cidade como um ente de negócios (empresa) e a cidade como um espaço para o cidadão (pátria), levantando, segundo Almeida e Engel (2017), o seguinte questionamento: "Se a cidade é um produto, este é vendido para quem? Para os cidadãos ou para quem é de fora?" (ALMEIDA; ENGEL, 2017, p. 91). Deste modo, a segregação espacial e a má distribuição de rendas acabam por ser reforçadas por esse modelo de gestão, contribuindo para o aumento da pobreza mesmo em cidades desenvolvidas (HARVEY, 1996).

Na perspectiva de Ocke e Ikeda (2014), a crítica principal ao modelo reside no fato de que a construção de uma imagem urbana perfeita serve não apenas como catalizadora das desigualdades sociais, mas também como uma ferramenta que desvia a atenção da população dos problemas e necessidades locais. Assim, a aprovação da população local a respeito das práticas de city marketing é obtida através de um processo de falsa consciência.

\section{Belo Horizonte pela perspectiva do empresariamento urbano}

Seguindo a visão de Castells e Borja (1996) de que o planejamento estratégico é a principal ferramenta disponível para que a gestão local seja capaz de alterar a realidade da cidade, a Prefeitura de Belo Horizonte lançou, em 2009, a primeira versão do Plano estratégico da cidade - PEBH 2030, cuja perspectiva empreendedora e plural de gestão urbana orientou a organização e a formulação de diretrizes e metas para a administração da cidade nos úitmos dez anos (entre 2009 e 2019)3․ A gestão da cidade, a partir da definição de um planejamento estratégico de médio e longo prazo, com a definição das diretrizes e metas a serem alcançadas,

\footnotetext{
${ }^{3}$ Importante ressaltar que, em meados de julho de 2019, o Decreto no 17.135/2019 revogou o PEBH 2030, definindo a Agenda 2030 dos Objetivos de Desenvolvimento Sustentável da Organização das Nações Unidas (Agenda ODS da ONU) como referência para o planejamento estratégico de médio e longo prazo de ações e programas das políticas públicas a serem adotados no município, para a promoção do seu desenvolvimento econômico, social, ambiental e institucional.
} 
visa seu desenvolvimento socioeconômico e melhor posicionamento no cenário regional, nacional e global.

A adoção da análise SWOT para a elaboração do PEBH 2030, com o objetivo de identificar seus pontos fortes e fracos, as oportunidades e ameaças, permitiu o diagnóstico situacional da municipalidade, além de fornecer as estratégias e medidas necessárias à alteração de sua realidade e à melhoria do seu desempenho na competição interurbana (MACEDO, 2012). A utilização do plano estratégico como forma de propor ações a longo prazo, voltadas à execução de projetos fundamentais para o desenvolvimento urbano, foi realizada visando à captação de recursos para a cidade, cuja série de ferramentas são identificadas na figura 1.

Figura 1 - Fluxograma empresariamento urbano

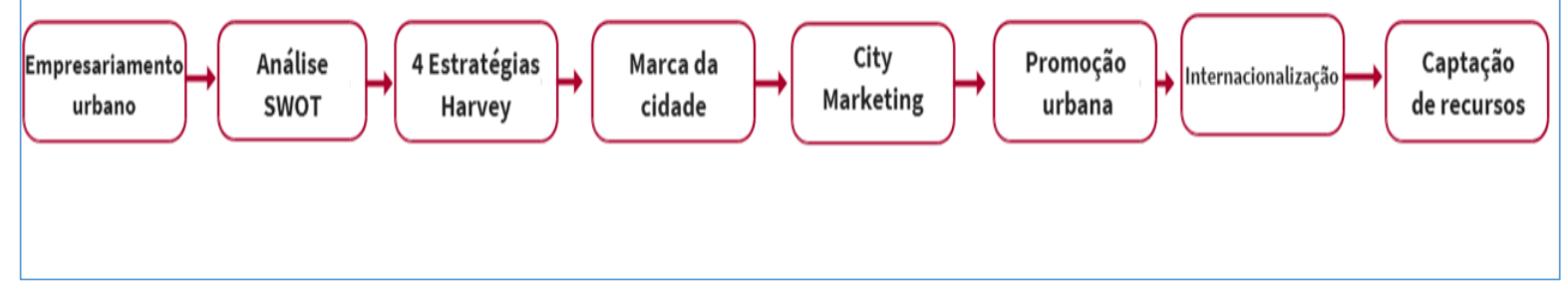

Fonte: elaborado pelos autores a partir de Harvey (1996)

Elaborado de forma a contemplar tanto o período de curto e médio prazo (BH Metas e resultados), quanto o longo prazo (BH 2030), o plano possuía três versões, tendo como visão de futuro a de uma "cidade de oportunidades, sustentável e com qualidade de vida", a qual, para ser cumprida contava com uma estrutura dividida em objetivos, metas e áreas de resultado.O PEBH 2030 visava estabelecer as diretrizes para o desenvolvimento econômico, garantir maior atratividade para investimentos, promover a melhoria da qualidade de vida e, finalmente, criar uma imagem positiva da cidade (PREFEITURA MUNICIPAL DE BELO HORIZONTE, 2009), capacitando-a, nos termos de Castells e Borja (1996), para uma maior inserção e visibilidade no cenário mundial.

Assim, o PEBH 2030 estabeleceu uma correspondência entre a imagem atrativa e positiva que se pretende para a cidade e os atributos que deverão caracterizá-la como uma cidade do futuro ${ }^{4}$, quais sejam: "cidade de oportunidades"; "cidade saudável"; "cidade com

\footnotetext{
${ }^{4}$ Apesar da recente alteração do Plano Diretor de Belo Horizonte, por intermédio da Lei no 11.181/2019, bem como da adoção das diretrizes da Agenda ODS da ONU pelo poder público municipal, observa-se que as propostas de desenvolvimento para a cidade previstas no PEBH 2030 são compatíveis com os objetivos estratégicos e as diretrizes da política de desenvolvimento urbano atualmente implementados no município.
} 
mobilidade"; "cidade segura"; "cidade com todas as vilas vivas"; "cidade compartilhada"; "cidade sustentável"; "cidade de todos" (PREFEITURA MUNICIPAL DE BELO HORIZONTE, 2009, p. 34).

No mesmo sentido, constata-se a utilização da internacionalização, do city marketing e suas ferramentas (apoio populacional por meio da participação popular; promoção de eventos e atrações que geram satisfação nos moradores e visitantes; branding para a constituição da imagem da cidade e infraestrutura urbana - Figura 2), como meios para o desenvolvimento econômico do município, tornando clara a orientação pela competição interurbana e para a captação de recursos.

Figura 2 - Ferramentas do city marketing

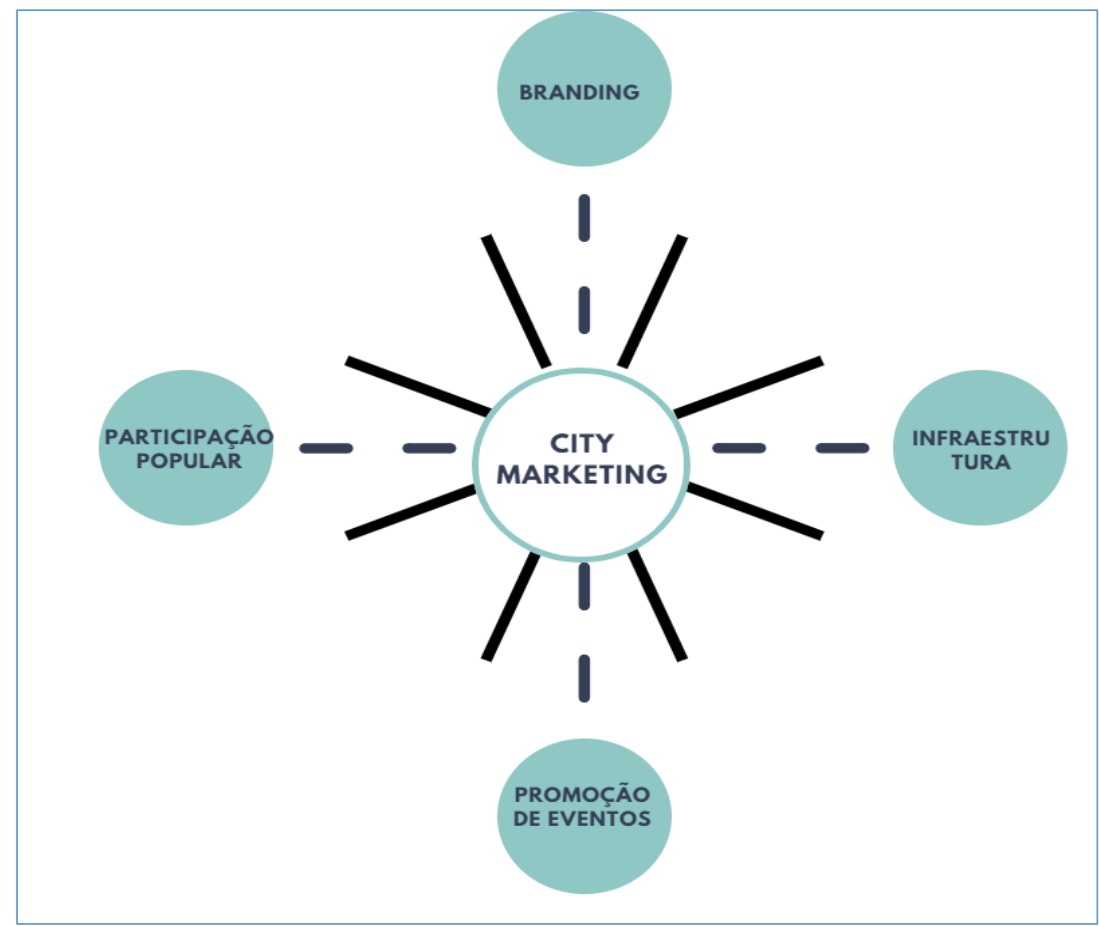

Fonte: elaborado pelos autores a partir de Almeida (2004).

A partir do fluxo proposto na figura 1 e das ações de marketing urbano implementados pela Prefeitura de Belo Horizonte, pela ótica das ferramentas (infraestrutura, participação popular e branding) e objetivos (internacionalização e promoção urbana) do city marketing, verifica-se uma série de práticas destinadas à promoção de Belo Horizonte no cenário urbano internacional e à captação de recursos para a cidade.

\section{Resultados e discussão}

O PEBH 2030 - com seus objetivos, metas e resultados almejados -, foi concebido a 
partir da análise do ambiente, possibilitada pela matriz SWOT, cuja avaliação das potencialidades da cidade e seu posicionamento no cenário local-global permitiu identificar a realidade de Belo Horizonte e os possíveis caminhos futuros a serem seguidos, corroborando a visão de Dantas e Melo (2008), de que a análise SWOT é peça fundamental para a percepção do posicionamento.

Veja-se que, a última versão do PEBH 2030 abarca um significativo número de menções a termos chaves associados ao city marketing, indicando o fortalecimento das ações e diretrizes estabelecidas pelo governo municipal para o efetivo alcance dos resultados esperados com a sua concepção: internacionalização, captação de recursos e desenvolvimento socioeconômico (Quadro 2). Há, pois, um estímulo à promoção da cidade no cenário local-global, com reforço da utilização das ferramentas dispostas pelo city marketing.

Quadro 2 - Repetição de termos associados ao city marketing no Plano Estratégico

\begin{tabular}{|l|c|c|c|}
\hline TERMO & $\begin{array}{c}\text { № de vezes que } \\
\text { aparece na versão 2009 }\end{array}$ & $\begin{array}{c}\text { № de vezes que } \\
\text { aparece na versão 2010 }\end{array}$ & $\begin{array}{c}\text { № de vezes que } \\
\text { aparece na versão } 2015\end{array}$ \\
\hline Internacionalização & 1 & 1 & 11 \\
\hline Internacional & 6 & 10 & 46 \\
\hline Promoção & 11 & 29 & 74 \\
\hline Marketing & 0 & 0 & 3 \\
\hline Branding & 0 & 0 & 0 \\
\hline Participação popular & 4 & 5 & 11
\end{tabular}

Fonte: Elaborado pelos autores

A partir do Quadro 2, é possível perceber o aumento da incidência de termos associados ao empresariamento entre as versões 2009/2010 do PEBH 2030 e a última versão (2015). Nesse aspecto, a menção aos termos "internacionalização" e "internacional" aumenta significativamente. As versões do PEBH 2030 de 2009 e 2010 fazem apenas uma menção à palavra internacionalização (em ambos os casos se referindo a necessidade de ampliação do nível de internacionalização de Belo Horizonte). Na versão de 2015, por sua vez, percebe-se uma intensificação na utilização destes termos, sendo que, na grande maioria das vezes, a internacionalização é colocada como um objetivo da área de prosperidade, representando um importante papel na atração, geração e retenção de investimentos estrangeiros, bem como na inserção das empresas locais no mercado externo. Mas, ainda que a internacionalização represente um importante papel, não é ela o objetivo final. Tal fato reforça a visão de Macedo (2012, p. 189), de que "ao contrário do argumento proposto - de que o planejamento estratégico de BH é uma ferramenta para sua internacionalização -, é a internacionalização da 
cidade que serve aos propósitos do BH Metas e Resultados e à gestão estratégica da cidade".

De todo modo, a maior importância dada à internacionalização nos últimos anos pode ser vista como um indicativo de uma maior preocupação com a projeção internacional de Belo Horizonte e sua inserção nas redes internacionais de cidades. Confirmando esta perspectiva, o Diretor Geral de Projetos Estratégicos da Prefeitura Municipal de Belo Horizonte - Luís Otávio Milagres de Assis - afirma que isto ocorre da seguinte forma:

\footnotetext{
"Temos que correr atrás de alternativas de crescimento econômico, então na hora que você procura internacionalizar, não é internacionalizar por internacionalizar. Belo Horizonte precisa de uma dinâmica econômica social, temos diversos concorrentes com atribuições semelhante, Curitiba por exemplo. Então, temos que buscar trazer o máximo possível de empresas para cá."
}

Para garantir a efetivação destes objetivos, o PEBH 2030 encampa as ações da Secretaria Municipal Adjunta de Relações Internacionais (SMARI) - órgão especializado na interação entre a prefeitura e atores internacionais -, conduzindo as políticas e ações do município visando à negociação e captação de investimentos estrangeiros, a fim de transformá-lo num centro convergente da economia local e regional e em agente articulador de intercâmbios nacionais e internacionais (PREFEITURA MUNICIPAL DE BELO HORIZONTE, 2009). Vale ressaltar que, atualmente, a SMARI encontra-se como subordinada da Secretaria Municipal de Desenvolvimento, passando de Secretaria para Diretoria de Relações Internacionais (DIRI). O reposicionamento da SMARI dentro da Secretaria responsável pelo viés econômico do município, reforça, mais uma vez, a visão de Macedo (2012) de que a internacionalização é tratada como um meio para a captação de recursos e desenvolvimento econômico da cidade, além de encaixar-se perfeitamente na estrutura do Plano estratégico; uma vez que é justamente no objetivo econômico deste que encontramos as menções ao termo “internacionalização".

Dentre as propostas direcionadas à internacionalização da cidade, a SMARI foi responsável pela execução das seguintes ações: (i) acordos de parcerias e cooperação com entidades internacionais; (ii) redes internacionais de cooperação; (iii) Belo Horizonte como sede de vários eventos internacionais: Congresso de Centro Ibero-Americano de Desenvolvimento Estratégico Urbano (CIDEU), MercoCidades, Congresso Mundial do ICLEI, entre outros, cuja realização constitui-se como uma importante ferramenta do city marketing, por permitir a divulgação internacional da cidade e, segundo Kavaratzis (2005), a "comunicação secundária" do place branding.

A baixa divulgação das ações, contudo, impossibilita a análise dos resultados alcançados 
com as iniciativas e eventos realizados pela SMARI, não havendo informações concretas quanto aos benefícios e investimentos gerados a partir da realização destes eventos.

A palavra promoção por sua vez, no sentido de publicitar, é mencionada em seis oportunidades e está associada à promoção comercial, turística e cultural da cidade,como forma de captar investimentos e garantir sua internacionalização. A construção da imagem urbana de Belo Horizonte gira em torno de uma imagem de modernidade e diversificação, o que fica claro através das ações da prefeitura principalmente em torno do turismo e da cultura, assim como em suas tentativas de captação de eventos ligados a moda, lazer, esportes, tecnologia e design.

Belo Horizonte dispõe, hoje, de uma ampla variedade de atrativos capazes de impulsionar o processo de promoção da cidade. Segundo dados do Ministério do Turismo (2015), Belo Horizonte foi a cidade que mais cresceu em relação a oferta de produtos turísticos, classificando-se em 5 a lugar na lista de destinos indutores. Com uma expansão cada vez maior no setor de eventos, assim como o fato de possuir o maior complexo Cultural da América Latina, com seu conjunto de museus (BELOTUR, 2017), Belo Horizonte conta ainda com atrações na área ambiental (aquário de peixes, parque ecológico, jardim japonês e Mirante Mangabeiras), além do Conjunto Moderno da Pampulha recentemente intitulado como patrimônio cultural da humanidade pela UNESCO.

A cidade passa também por melhorias significativas em sua infraestrutura turística, contando com modernização na logística de transportes (Sistema BRT - Bus Rapid Transit, expansão do Aeroporto Internacional Tancredo Neves e sua transformação em aeroporto indústria), nova sinalização indicativa, iluminação pública e manutenção de seus patrimônios.

De igual modo, Belo Horizonte tem investido cada vez mais em soluções inteligentes para a infraestrutura urbana, ocupando, atualmente, o 13ㅇ lugar geral no ranking Connected Smart Cities (URBAN SYSTEMS, 2019). A cidade abriga mais de 200 startups, a maioria localizada no San Pedro Valley, que possui, hoje, alta concentração de empresas voltadas para o ramo tecnológico. Tais empresas alimentam o ambiente de inovação, a partir de aceleradoras, investidores, etc., que incentivam a cultura da colaboração e fazem de Belo Horizonte uma referência em criatividade, negócios e resultados em tecnologia 5 .

Assim, o cenário atual é promissor para a cidade, o que fica evidente a partir dos

\footnotetext{
${ }^{5}$ Desde 2018, a cidade de Belo Horizonte integra a Rede Fab City, na França, sendo a segunda cidade do Brasil a participar dessa iniciativa. A rede conecta 34 cidades ao redor do mundo que visam alterar o paradigma da economia industrial atual, a partir da implementação de modelos urbanos associados ao desenvolvimento sustentável. 
seguintes dados: (i) 1a lugar em relação a evolução dos atrativos turísticos do Índice de Competitividade 65 Destinos Indutores em 2014; (ii) 5a lugar entre o Índice Geral dos 65 Destinos Indutores; (iii) 4ạ lugar no índice de marketing e promoção urbana dos 65 Destinos Indutores; (iv) 7ạ cidade que mais realiza eventos internacionais pelo ranking ICCA; (v) Alto índice de satisfação dos turistas: 93,6\% dos turistas pretendem voltar à cidade; (vi) 3ạ cidadesede mais visitada durante a Copa do Mundo FIFA 2014 - 20\% do fluxo nacional (MINISTÉRIO DO TURISMO, 2015; BELOTUR, 2017).

Por outro lado, ressalta-se a utilização do termo promoção associada ao aspecto social, evidenciando outra ferramenta do city marketing: a participação popular. Ao promover a participação popular, o PEBH 2030 busca erigir uma cidade inclusiva e de todos, proporcionando diretrizes para o empoderamento feminino e LGBT, a inclusão de deficientes e a garantia de cidadania para pessoas em situação de rua; criando um senso de "patriotismo cívico", de identificação e de pertencimento nos moradores da cidade.

Como expectativas para a cidade, O PEBH 2030 sugere possíveis posicionamentos a serem seguidos, identificando alguns atributos em Belo Horizonte que, segundo o Gerente de Monitoramento e Estudos da Belotur - Eduardo Henrique de Paula Cruvinel, serviram de base para a instituição da marca e posicionamento atual da cidade: "Belo Horizonte Surpreendente", a partir da estruturação da $3^{a}$ v versão do Plano de Marketing de Belo Horizonte, finalizada em 2012, em parceria público-privada com a empresa Chias Marketing referência mundial em projetos de planejamento estratégico de marketing turístico.

Percebe-se, também, a inclusão da palavra marketing na última versão do PEBH 2030, indicando, mais uma vez, a intensificação das questões ligadas ao city marketing. Pontua-se, inclusive, a necessidade de elaboração de um novo plano de marketing 2015/2020.

A existência do Plano de Marketing para a cidade, evidencia a apropriação de ferramentas até então exclusivas da iniciativa privada por parte da administração pública municipal, deixando clara a lógica do empresariamento urbano e a inserção da cidade em um ambiente mais corporativo, tornando-a o produto a ser vendido (VAINER, 2002).

No plano em questão, essa perspectiva de cidade-produto é evidenciada, uma vez que este, com base em uma pesquisa de mercado - outra ferramenta do meio privado adaptada para a gestão pública - elenca 95 produtos de Belo Horizonte, sendo estes o que têm maior valor de mercado e que foram agrupados em eixos temáticos de acordo com sua tipologia (Quadro 3).

Os segmentos estabelecidos no quadro mostram profunda relação com as estratégias de Harvey (1996), uma vez que estes recorrem a exploração dos recursos e vantagens da cidade 
e a divisão espacial do consumo, como forma de garantirem a promoção da cidade. Diante desta perspectiva, comprova-se a importância da identificação das estratégias pertinentes à cidade para a elaboração do Plano de Marketing.

Quadro 3 - Produtos turísticos de Belo Horizonte

\begin{tabular}{|l|r|}
\hline \multicolumn{2}{|c|}{ Tipologia dos produtos turísticos de Belo Horizonte } \\
\hline Museus e equipamentos culturais & 26 \\
\hline Parques naturais e áreas verdes & 5 \\
\hline Praças, mirantes e áreas urbanas & 8 \\
\hline Mercados, feiras e compras & 13 \\
\hline Identidade cultural urbana e serviços & 11 \\
\hline Eventos culturais, esportivos e de negócios & 18 \\
\hline Espaços para eventos estádios e centros esportivos & 9 \\
\hline Entorno de BH & 5 \\
\hline
\end{tabular}

Fonte: Adaptado de Chias Marketing (2012).

A concepção de venda da cidade é evidenciada pelas diretrizes estabelecidas no PEBH 2030 e pelos posicionamentos propostos pelo Plano de Marketing; o que nos leva ao encontro das expectativas, ações e eventos propostos para trabalhar estes aspectos ao longo dos anos, permitindo que façamos uma linha do tempo - demonstrada na Figura 3 -, que represente as ações tomadas pela gestão pública em Belo Horizonte no tocante aos aspectos voltados ao city marketing da cidade.

Figura 3 - Linha do tempo de Belo Horizonte

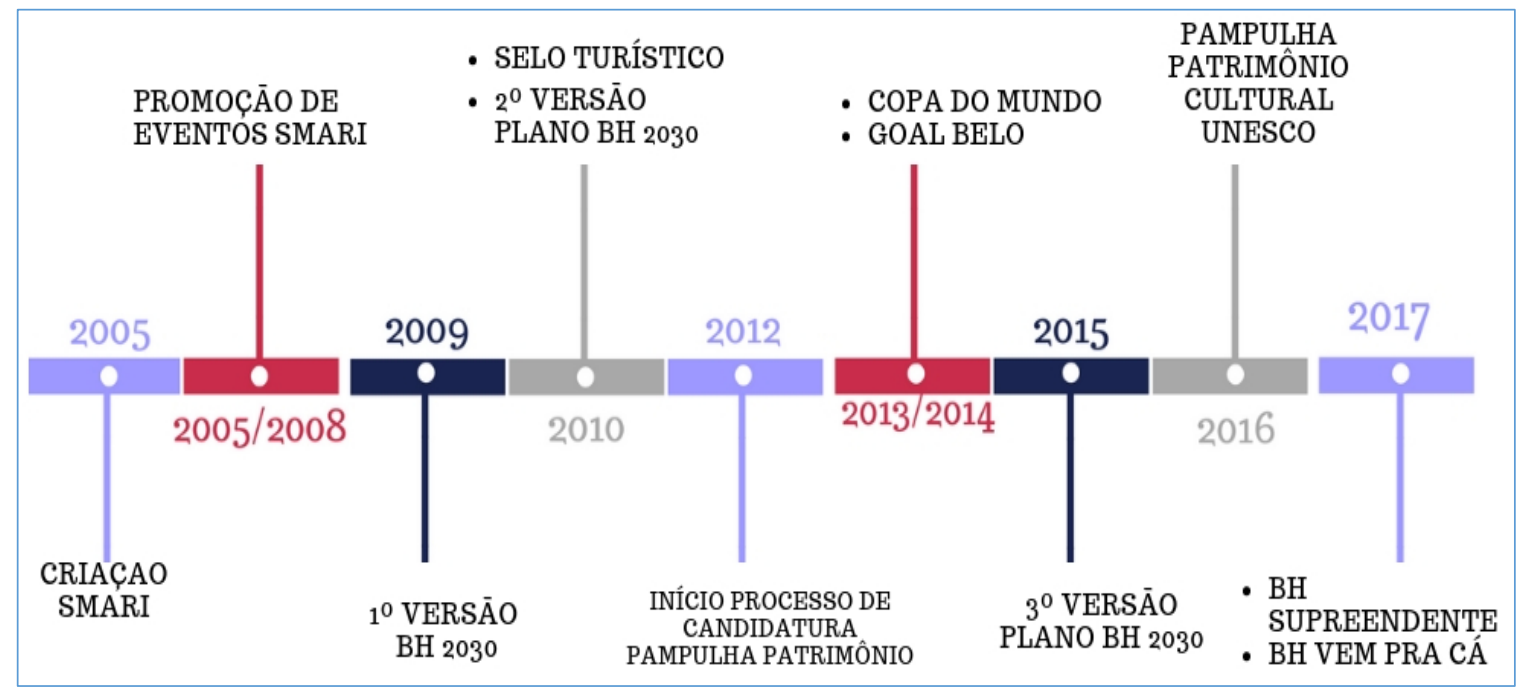

Fonte: elaborado pelos autores 
Assim, o PEBH 2030, além de definir as características almejadas para a configuração futura da cidade, elenca as principais ações que a administração municipal deverá encampar para o desenvolvimento da cidade e sua promoção no mercado interurbano. Ações estas que estão intimamente relacionadas com as ferramentas e objetivos do city marketing, cuja implementação (ou não) pela Poder Público, individualmente ou em parceria com a iniciativa privada, estão demonstradas no Quadro 4.

Vale lembrar que a perspectiva de branding é vista por Kavaratzis (2005) como primária, quando a comunicação da marca em si não é o objetivo principal, e secundária, quando a divulgação da marca ocorre de maneira intencional, em consonância com o restante das práticas desenvolvidas pela cidade. Assim, o Carnaval e o Arraial, por exemplo, acabam trabalhando essa perspectiva ativamente, uma vez que, a divulgação destes ocorre de modo intencional para promover a nova imagem da cidade: a de uma cidade jovem e plural.

Quadro 4 - Ações em Belo Horizonte x Diretrizes do city marketing contempladas

\begin{tabular}{|c|c|c|c|c|c|c|c|c|}
\hline \multirow{2}{*}{\multicolumn{2}{|c|}{$\begin{array}{l}\begin{array}{l}\text { Ferramentas/ } \\
\text { objetivos }\end{array} \\
\text { Ações PBH }\end{array}$}} & \multirow[b]{2}{*}{ Infraestrutura } & \multirow[b]{2}{*}{$\begin{array}{c}\text { Participação } \\
\text { popular }\end{array}$} & \multicolumn{2}{|c|}{ Branding } & \multirow[b]{2}{*}{$\begin{array}{c}\text { Promoção } \\
\text { de } \\
\text { eventos }\end{array}$} & \multirow[b]{2}{*}{$\begin{array}{c}\text { Promoção } \\
\text { urbana }\end{array}$} & \multirow[b]{2}{*}{ Internacionalização } \\
\hline & & & & $\begin{array}{l}\text { Com. } \\
\text { Primária }\end{array}$ & $\begin{array}{l}\text { Com. } \\
\text { Secundária }\end{array}$ & & & \\
\hline \multicolumn{2}{|c|}{ Plano estratégico } & $\checkmark$ & $\checkmark$ & $\checkmark$ & $x$ & $\checkmark$ & $\checkmark$ & $\checkmark$ \\
\hline \multicolumn{2}{|r|}{ SMARI } & $x$ & $x$ & $\checkmark$ & $x$ & $\vee$ & $\checkmark$ & $\checkmark$ \\
\hline \multicolumn{2}{|c|}{$\begin{array}{c}\text { Copa do Mundo } \\
2014\end{array}$} & $\checkmark$ & $\checkmark$ & $\checkmark$ & $\checkmark$ & $\checkmark$ & $\checkmark$ & $\checkmark$ \\
\hline \multicolumn{2}{|c|}{ Goal Belo! } & $x$ & $x$ & $\checkmark$ & $x$ & $\vee$ & $\checkmark$ & $\checkmark$ \\
\hline \multicolumn{2}{|c|}{$\begin{array}{l}\text { Pampulha } \\
\text { patrimônio } \\
\text { UNESCO }\end{array}$} & $\checkmark$ & $\checkmark$ & $\checkmark$ & PARCIAL & $\checkmark$ & $\vee$ & $\checkmark$ \\
\hline \multirow{4}{*}{ 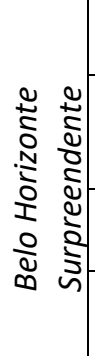 } & Carnaval & $\checkmark$ & $\checkmark$ & $\checkmark$ & $\checkmark$ & $\checkmark$ & $\checkmark$ & PARCIAL \\
\hline & $\begin{array}{l}\text { Arraial de } \\
\quad \text { Belo }\end{array}$ & $\checkmark$ & $\checkmark$ & $\checkmark$ & $\checkmark$ & $\checkmark$ & $\checkmark$ & PARCIAL \\
\hline & Gastronomia & $x$ & $\checkmark$ & $\checkmark$ & PARCIAL & $\checkmark$ & $\checkmark$ & PARCIAL \\
\hline & $\begin{array}{c}\text { Turismo } \\
\text { inteligente }\end{array}$ & $\checkmark$ & $x$ & $\checkmark$ & $\checkmark$ & $\checkmark$ & $\checkmark$ & $\checkmark$ \\
\hline
\end{tabular}

Fonte: Elaborado pelos autores.

Assim, temos o PEBH 2030 contemplando, basicamente, todas as ferramentas e objetivos do city marketing, menos a comunicação intencional da marca da cidade, ou seja, o 
branding secundário, o que é percebido até mesmo pela ausência do termo no referido documento.

A SMARI, por ter como foco a internacionalização não aborda questões de infraestrutura e participação popular, uma vez que os eventos por ela promovidos têm pouca aderência dos cidadãos em si. Por outro lado, a partir da realização de eventos há a promoção da cidade e potencializa-se sua internacionalização.

A Copa do mundo, um evento de imensas proporções por si só, exatamente por sua abrangência consegue contemplar todos os aspectos abordados, promovendo melhorias na infraestrutura urbana, incluindo obras, programas e projetos que visavam adaptar a cidade às expectativas do público. Conscientes do papel do branding como potencializador da promoção do destino, em meio ao movimento de preparação para a Copa, uma nova marca turística foi criada para a cidade. De igual modo, promoveu-se ações e eventos comemorativos como forma de integrar a população local à realização da Copa do Mundo. A Copa colaborou também para evidenciar, na prática, uma das maiores críticas ao city marketing: a de que a partir do momento em que a cidade vira um produto a ser vendido, sua promoção visa muito mais atender às necessidades da minoria detentora do capital e do poder de investimento, do que as de seus moradores (ALMEIDA; ENGEL, 2017).

Pegando "carona" na Copa, o Goal Belo conseguiu contribuir de modo significativo para a internacionalização e promoção de Belo Horizonte, fortalecendo a perspectiva de uma cidade atrativa para investimentos e negócios. Através do Goal, a gestão municipal divulgou a cidade para investidores internacionais em eventos realizados na Espanha, México, Estados Unidos, Uruguai, entre outros países. O projeto englobou três esferas econômicas: tecnologia da informação, ecossistemas de startups e biotecnologias, setores modernos que, ao serem escolhidos como temas do projeto passam também a impressão de modernidade e inovação de Belo Horizonte.

A Pampulha, sempre peça fundamental na promoção da imagem de Belo Horizonte, consegue, com a nomeação como Patrimônio Cultural da UNESCO promover ainda mais a cidade e seus atrativos, inserindo-os no campo do consumo cultural, onde a cultura ganha também, função econômica (PAES-LUCHIARI, 2006). Assim, o título atribuído ao Conjunto Moderno da Pampulha foi capaz de proporcionar melhorias na infraestrutura e a promoção de eventos para sua divulgação, uma vez que o valor econômico agregado a suas paisagens passa a ser sustentado por um discurso de valorização da cultura, qualidade ambiental e qualidade de vida - novos ingredientes da atribuição de valor das paisagens urbanas (PAES-LUCHIARI, 2006). 
Reforçando o place branding como uma estratégia que promove e fortalece a imagem de determinado destino, a nova perspectiva trazida pelo Belo Horizonte Surpreendente consegue abranger, de diferentes formas, todas as esferas trabalhadas, tendo o Carnaval e o Arraial como peças fundamentais para o cumprimento de diversos fatores, uma vez que estes são capazes de gerar grande participação popular, melhorias significativas na infraestrutura destes eventos, branding e promoção urbana, uma vez que o retorno positivo da realização destes impulsiona o nome da cidade de Belo Horizonte. Assim, a nova marca (Belo Horizonte Surpreendente) trabalha a imagem da cidade sob diferentes perspectivas: uma cidade atrativa tanto para turismo de negócio quanto para o cultural, de gastronomia única, entorno histórico, eventos esportivos, o perfil jovem e a capacidade para desenvolver negócios tecnológicos.

Quanto à internacionalização, embora de modo natural estes eventosproporcionem a divulgação no cenário internacional, de acordo com Eduardo Henrique de Paula Cruvinel, Gerente de Monitoramento e Estudos da Belotur, o objetivo de divulgação dos mesmos ainda tem pouco foco na internacionalização, preocupando-se muito mais em expandir o evento para o público nacional.

O turismo inteligente, pelo destaque que tem dado a Belo Horizonte, consegue promover também a internacionalização da cidade, além de trabalhar a perspectiva da infraestrutura de uma maneira diferente das outras ações: com foco na melhoria tecnológica.

\section{Considerações Finais}

Num tempo em que tudo tende à mercantilização e que o valor de troca se sobrepõe ao valor de uso, as cidades capitalistas ajustam a sua configuração espacial às novas necessidades da economia. A partir de ambiciosos projetos estratégicos e mediante ações de city marketing, as cidades "vendem" sua imagem no competitivo mercado interurbano, a fim de atrair investidores, turistas e consumidores que intensifiquem seu crescimento econômico e desenvolvimento.

Contudo, ao adotar a lógica do empresariamento urbano para prover o desenvolvimento da cidade, por vezes o Poder Público acaba colocando interesses privados em primeiro plano, desvirtuando sua função pública e os princípios de uma gestão democrática e plural, pois há uma transferência de recursos públicos para a esfera privada em detrimento de investimentos para a melhoria de serviços sociais, como moradia, educação, saúde, segurança e lazer.

De outra parte, há significativas diferenças entre o contexto e a forma de gestão de uma organização privada e aqueles inerentes à gestão pública, principiando pelo fato de uma empresa 
visar prioritariamente o lucro e a geração de valor para seus acionistas. Depois, pelo fato de haver autonomia na forma de gestão e de aplicação de recursos financeiros para o alcance das metas de médio e longo prazo definidas no seu respectivo planejamento estratégico. O Poder Público, por sua vez, deve orientar suas ações com base estritamente legal, fazendo somente aquilo que a lei autoriza; deve observar as metas e prioridades estabelecidas nas diretrizes orçamentarias para o exercício financeiro subsequente e, sobretudo, deve objetivar a estruturação de uma cidade que garanta qualidade de vida e bem-estar para todos os seus cidadãos.

Além da divergência quanto aos fins, a aplicação de ferramentas associadas ao modelo de gestão empresarial na cidade está sujeita a desafios distintos daqueles vivenciados pelas organizações privadas, como a ausência de continuidade dos programas e metas definidos no plano de governo em razão da alternância política. Outros entraves são a burocracia do serviço público; a dificuldade de conciliar prioridades entre as diversas áreas de administração pública e os impactos provocados por variáveis externas, como o cenário de crise econômica atualmente vivenciado pelo país, cujos reflexos nos municípios provocam contingências orçamentárias e entraves à implementação dos programas e ações pela gestão pública.

Nesse sentido, é imprescindível a implementação de projetos e políticas públicas que promovam o desenvolvimento da cidade de forma sistêmica, igualitária, em todas as suas nuances (sociais, econômicas, ambientais), e não apenas seu caráter empresarial ou de produto a ser consumido. O tema é amplo e merece ser estudado e complementado por trabalhos futuros que avaliem a evolução e os efeitos das práticas de empresariamento urbano, sobretudo se consideradas as perspectivas de médio e longo prazo dos planos estratégicos de desenvolvimento socioeconômico previstos para a cidade de Belo Horizonte.

\section{Referências}

ABRANTES, P. O modelo Barcelona: um exame crítico. Finisterra, Lisboa, 90, 211-213, 2010. ALMEIDA, C. C. O marketing das cidades. Gestão e desenvolvimento, Viseu, n. 12, p.945,2004 .

ALMEIDA, G. G. F.; ENGEL, V. A cidade-mercadoria e o marketing urbano na (re)construção da imagem dos espaços públicos: o caso da marca da cidade do Rio de Janeiro. Rev. Bras. Estud. Urbanos Reg., Recife, v. 19, n. 1, p. 89-105, jan./abr. 2017.

ARAÚJO, F. F. Empresariamento Urbano: concepção, estratégias e críticas. Conferência do Desenvolvimento, 2011. Anais do I circuito de debates acadêmicos.

BELOTUR. Planejamento Estratégico 2017-2021: Belo Horizonte-Destino Turístico Inteligente. 2017. 
BRESSER-PEREIRA, L. C.; CUNILL-GRAU, N. Entre o Estado e o mercado: o público nãoestatal. In: BRESSER-PEREIRA, L. C.; CUNILL-GRAU, N. (Orgs.). O público não-estatal na reforma do Estado. Rio de Janeiro: Editora Fundação Getúlio Vargas/CLAD, 1999, p. 1548.

CARVALHO, M. Cidade Global: anotações críticas sobre um conceito. São Paulo Perspec., São Paulo, v. 14, n. 4, p. 70-82, out. 2000.

CASTELLS, M.; BORJA, J. As cidades como atores políticos. Novos Estudos CEBRAP, São Paulo, n. 45, jul. 1996, p. 152-166.

CHESNAIS, F. Mundialização: o capital financeiro no comando. Revista Outubro, n. 5, 2001, p. 728.

COMPANS, R. O paradigma das global cities nas estratégias de desenvolvimento local. Revista Brasileira de Estudos Urbanos e Regionais, Campinas, n. 1, p. 91-114, mai, 1999.

DALLABRIDA, V. R.; TOMPOROSKI, A. A.; SAKR, M. R. Do marketing territorial ao branding de território: concepções teóricas, análises e prospectivas para o Planalto Norte Catarinense. Interações (Campo Grande), Campo Grande, n. 4, v. 17, p. 671-685, dez. 2016.

DANTAS, N. G. S.; MELO, R. S. O método de análise SWOT como ferramenta para promover o diagnóstico turístico de um local: o caso do município de Itabaiana. Caderno virtual de turismo, vol. 8, n. 1, p. $118-130,2008$.

DELGADILLO, V. Urbanismo a la carta: teorías, políticas, programas y otras recetas urbanas para ciudades latinoamericanas. Cad. Metrop., São Paulo, v. 16, n. 31, p. 89-111, jun,2014.

FERREIRA, A. F. Gestão Estratégica de Cidades e Regiões. 1. ed., Lisboa: Fundação Calouste Gulbenkian, 2005.

FIX, M. A. A fórmula mágica da parceria público-privada: Operações Urbanas em São Paulo. Urbanismo: dossiê São Paulo. Rio de Janeiro. p. 185-198, 2004.

GOTTDIENER, M.; FEAGIN, J. R.. Uma mudança de paradigma na sociologia urbana. Tradução Hélio Alan Saltorelli. Espaço \& Debates, São Paulo, ano IX, n. 28, p. 44-58, 1989.

HARVEY, D. Do gerenciamento ao empresariamento: a transformação da administração urbana no capitalismo tardio. Revista de Estudos Regionais e Urbanos, São Paulo, n. 39, p.4864, 1996.

HARVEY, D. A produção capitalista do espaço. Tradução Carlos Szlak. São Paulo: Annablume, 2005.

HARVEY, D. Condição Pós-Moderna: uma pesquisa sobre as origens da mudança cultural. 21. ed., São Paulo: Loyola, 2011.

KAVARATZIS, M. Place branding: a review of trends and conceptual model. The Marketing Review, v. 5, 2005, p. 329-342. Recuperado a partir de: <http://sv407.oddgeirtveiten.com/wpcontent/uploads/2015/12/Kavaratzis-Plaxce-Branding.pdf>.

KOTLER, P.; HAIDER, D. H.; REIN, I. Marketing Places: attracting investment, industry, and tourism to cities, states, and nations. Free Press, New York, 1993.

KOTLER, P.; GERTNER, D. Country as Brand, Product, and Beyond: A Place Marketing and Brand Management Perspective. The Journal of Brand Management, v. 9, p. 249-261, Apr. 2002. Recuperado a partir

de: $<$ https://edisciplinas.usp.br/pluginfile.php/1680885/mod resource/content/1/Artigos/Country 
as brand.pdf>.

LEFEBVRE, H. A produção do espaço. Tradução Doralice Barros Pereira e Sérgio Martins. Primeira versão: início - fev. 2006

MACEDO, B. M. Considerações sobre o planejamento estratégico de Belo Horizonte e a internacionalização da cidade. Fronteira: Revista de Iniciação Científica em Relações Internacionais. v. 11, n. 22, 2012.

MINISTÉRIO DO TURISMO. Índice de Competitividade do Turismo Nacional. 2015.

OCKE, M. A. M.; IKEDA, A. A. Marketing de lugar: estado da arte e perspectivas futuras. Rev. Adm. (São Paulo), São Paulo, v. 49, n. 4, p. 671-683, Dez. 2014.

PAES-LUCHIARI, M. T. D. Patrimônio cultural: uso público e privatização do espaço urbano. Revista Geografia, Rio Claro, v. 31, n.1, p. 44-66, 2006.

PREFEITURA MUNICIPAL DE BELO HORIZONTE. Plano Estratégico BH 2030: A cidade que queremos. 2a versão. 2009.

RAINISTO, S. K.. Success factors of place marketing: a study of place marketing practice in northern Europe and the United States. 2003. $271 \mathrm{f}$. Dissertação (Doctor of Science in Technology) - Helsinki University of Technology, Helsinki, 2003. Recuperado a partir de: <http://bestplaceinstytut.org/www/wp-content/uploads/2010/10/dissertationRainisto.pdf>.

SÁNCHEZ, F. Políticas urbanas em renovação: uma leitura crítica dos modelos emergentes.

Revista Brasileira de Estudos Urbanos e Regionais, n. 1, mai. p. 115- 132, 1999.

SANTOS, C. R. S. Dos Negócios na Cidade à Cidade como Negócio: uma nova sorte de acumulação primitiva do espaço. Cidades, v. 03, n. 05, p. 101-122, jan./jun. de 2006.

SASSEN, S. As cidades na economia mundial. Tradução Carlos Eugênio Marcondes de Moura. São Paulo: Studio Nobel, 1998.

SILVA, E. R. O Planejamento Estratégico sem plano: uma análise do empreendedorismo urbano no Brasil. Revista de Geografia e Ordenamento do Território, n. 2, Centro de Estudos de Geografia e Ordenamento do Território. p. 279-306, Dez. 2012.

SILVA, E. C. Marketing Público: Uma plataforma de "trocas" no setor público. Revista Eletrônica de Administração, v. 14, n.1, jan./jun. 2015. Recuperado a partir de: <http://periodicos.unifacef.com.br/index.php/rea/article/view/748/809>.

THEODORE, N.; PECK, J.; BRENNER, N. Urbanismo neoliberal: la ciudad y el imperio de los mercados. Temas Sociales, Vol. 66. Santiago de Chile: Ediciones SUR, marzo, 2009. Recuperado a partir de: <http://www.sitiosur.cl/r.php?id=898>.

URBAN SYSTEMS. Ranking Connected Smart Cities 2019. Recuperado a partir de: <http://sators.rds.land/csc19_resultado_ranking>.

VAINER, C. B. Pátria, Empresa e Mercadoria: notas sobre a estratégia discursiva do planejamento estratégico urbano. In: ARANTES, O. B. F.; VAINER, C. B.; MARICATO, E. A cidade do pensamento único: desmanchando consensos. 3. ed, Petrópolis: Vozes, p. 75-103, 2002.

WARD, S. V. Selling places: the marketing and promotion of towns and cities 1850-2000. London: Spon Press, 2004. 